\title{
BMJ Open Does T wave inversion in lead aVL predict mid-segment left anterior descending lesions in acute coronary syndrome? A retrospective study
}

\author{
Nobuto Nakanishi, ${ }^{1}$ Tadahiro Goto, ${ }^{2}$ Tomoya Ikeda, ${ }^{1}$ Atsunobu Kasai ${ }^{1}$
}

To cite: Nakanishi N, Goto T, Ikeda T, et al. Does T wave inversion in lead aVL predict mid-segment left anterior descending lesions in acute coronary syndrome? A retrospective study. BMJ Open 2016;6:e010268. doi:10.1136/bmjopen-2015010268

- Prepublication history for this paper is available online. To view these files please visit the journal online (http://dx.doi.org/10.1136/ bmjopen-2015-010268).

Received 19 October 2015 Revised 10 December 2015 Accepted 7 January 2016

CrossMark

\footnotetext{
${ }^{1}$ Department of Cardiology, Ise Red Cross Hospital, Mie, Japan

${ }^{2}$ Department of Emergency Medicine, Massachusetts General Hospital, Boston, Massachusetts, USA
}

\section{Correspondence to} Dr Nobuto Nakanishi; nobuto_nakanishi@ise.jrc.or. jp

\section{ABSTRACT}

Objectives: Limited data are available regarding the predictive value of electrocardiographic $\mathrm{T}$ wave inversion in lead aVL for mid-segment left anterior descending (MLAD) lesions among patients with acute coronary syndrome (ACS).

Setting: Retrospective single-centre study, using a prospectively-collected coronary angiography database from January 2012 to December 2013.

Participants: We included consecutive adult patients with ACS who underwent urgent percutaneous coronary intervention $(\mathrm{PCl})$ within $24 \mathrm{~h}$ after arriving at the hospital. We excluded patients who did not undergo an ECG before $\mathrm{PCl}$, patients with proximal MLAD occlusion and patients diagnosed with vasospastic angina.

Primary and secondary outcome measures: The primary outcome was MLAD lesion $>50 \%$. The other outcome of interest was MLAD lesion as a cause of ACS. First, we evaluated the diagnostic values of $T$ wave inversion in lead aVL regardless of other T wave changes for each outcome. Second, we evaluated the diagnostic values of isolated T wave inversion in lead aVL.

Results: Overall, 219 patients were eligible for the analysis. T wave inversion in lead aVL regardless of other T wave changes had a sensitivity of $32.9 \%$, specificity of $48.2 \%$, positive predictive value of $27.6 \%$ and negative predictive value of $54.5 \%$ for predicting MLAD lesions. Isolated T wave inversion in lead aVL had a sensitivity of $9.8 \%$, specificity of $86.9 \%$, positive predictive value of $30.8 \%$ and negative predictive value of $61.7 \%$ for predicting MLAD lesions. These diagnostic values did not change materially when focusing on patients with MLAD lesion as the cause.

Conclusions: While T wave inversion in lead aVL regardless of other $T$ wave changes had low diagnostic values for predicting MLAD lesions, isolated T wave inversion in lead aVL had a high specificity. Our inferences underscore the importance of a cautious interpretation of T wave inversion in lead aVL among patients with ACS.

\section{INTRODUCTION}

The 12-lead ECG is a fundamental tool used to diagnose acute coronary syndrome (ACS)

\section{Strengths and limitations of this study}

- This is the first study to evaluate the diagnostic value of $T$ wave inversion in lead aVL for midsegment left anterior descending (MLAD) lesions among patients with acute coronary syndrome (ACS).

- Although previous studies demonstrated the usefulness of diagnostic values of $T$ wave inversion in lead aVL for MLAD lesions, our observation did not show the usefulness among patients with ACS.

- Since this study is a single-centre, retrospective study, the generalisability of our inferences might be limited.

- Our inferences underscore the importance of a cautious interpretation of $T$ wave inversion in lead aVL among patients with ACS.

because ST-T changes in ECG reflect myocardial ischaemia and myocardial necrosis after myocardial ischaemia. Based on the diagnosis and prediction of ischaemic lesions using ECG, cardiologists can provide early therapeutic intervention for patients with ACS. ${ }^{1} \mathrm{~T}$ wave inversion in lead aVL has been reported to be a reciprocal change of inferior wall infarctions, mostly caused by right coronary artery lesions. $^{23}$

However, several recent, small studies have suggested that $\mathrm{T}$ wave inversion in lead aVL is associated with mid-segment left anterior descending (MLAD) lesions. ${ }^{4-6}$ For example, a prospective observational study reported that the $\mathrm{T}$ wave inversion in lead aVL was significantly associated with a MLAD lesion in $>50 \%$ of patients with chronic stable angina. ${ }^{5}$ Another retrospective study from the USA, using data from 431 patients who underwent percutaneous coronary intervention (PCI), reported that the sensitivity of isolated $\mathrm{T}$ wave inversion in lead aVL for predicting a MLAD lesion in $>50 \%$ of patients was $76.7 \%$, and the specificity was $71.4 \% .^{4}$ However, 
these studies were conducted in limited population samples (eg, single-centre studies, including non-urgent PCI), thereby limiting the generalisability of their inferences for patients with suspected ACS. Despite the clinical significance of $\mathrm{T}$ wave inversion in lead $\mathrm{aVL}$ for the early detection of ischaemic lesions, the association between $\mathrm{T}$ wave inversion in lead aVL and a MLAD lesion $>50 \%$ of patients with ACS is yet to be elucidated.

To address this gap in the current literature, we aimed to investigate the diagnostic value of $\mathrm{T}$ wave inversion in lead aVL for MLAD lesions among patients who underwent urgent PCI for ACS.

\section{METHODS}

\section{Study design and settings}

This is a retrospective analysis using data from the coronary angiography (CAG) database at the Ise Red Cross Hospital from January 2012 to December 2013. The Ise Red Cross Hospital had 655 beds (medical and surgical), with approximately 243000 outpatients and 230000 admissions in 2013. There were 18000 emergency department visits, and 400 PCIs were performed annually (including 120 cases of urgent PCI for ACS). Since 1985, all CAG and PCI data have been prospectively collected for the CAG database. All data including patient's demographics, ECG findings, CAG findings and treatment data, were registered by cardiologists.

\section{Study population}

We included consecutive adult patients who underwent urgent PCI. Urgent PCI was defined as a PCI performed for patients with suspected ACS within $24 \mathrm{~h}$ after arriving at the hospital. ${ }^{78}$ In patients with suspected non-ST elevation myocardial infarction, board-certificated cardiologists assessed the need for coronary angiography based on the information on patient's symptoms, laboratory findings, ECG findings and ultrasonographic findings. We excluded patients who met the following criteria: (1) patients who did not undergo an ECG before PCI, (2) patients with complete occlusion of the left main trunk and proximal-segment left anterior descending artery (ie, we could not evaluate the MLAD lesion) and (3) patients diagnosed with vasospastic angina.

\section{T wave inversion}

Based on a joint recommendation of the American Heart Association (AHA), the American College of Cardiology Foundation (ACCP) and the Heart Rhythm Society (HRP) ${ }^{9}$ we defined the $\mathrm{T}$ wave inversion as $\mathrm{T}$ wave $\leq-0.1 \mathrm{mV}$, compared with the baseline from the end of the $\mathrm{T}$ wave to the beginning of the $\mathrm{P}$ wave (see online supplementary figure $1 \mathrm{~A}, \mathrm{~B})$. The $\mathrm{T}$ wave inversion in lead aVL was measured by cardiologists who were blinded to the results. In addition, we defined isolated T wave inversion as the presence of $\mathrm{T}$ wave inversion only in lead aVL regardless of ST elevation in other leads, using a previously described classification scheme for isolated $\mathrm{T}$ wave inversion (see online Supplementary figure $2 \mathrm{~A}, \mathrm{~B}) .{ }^{49}$

\section{Outcome and measured variables}

The primary outcome was MLAD lesion $>50 \%$. MLAD was defined as the first septal branch to the point where the left anterior descending artery forms an angle in the right anterior oblique view. ${ }^{10}$ The other outcome of interest was the MLAD lesion as the cause for ACS. The MLAD lesion as the cause for ACS was defined as (1) the MLAD lesion where PCI was performed or (2) the MLAD lesion diagnosed as the cause by the PCI operator in cases with multivessel disease. Data on patient demographics, including age, sex, smoking, family history of coronary artery diseases, hypertension, history of myocardial infarction, diabetes mellitus and dyslipidaemia, were collected from the database and medical charts of our hospital.

\section{Statistical analyses}

Continuous data were presented as the median (IQR), whereas categorical data were expressed as number (\%), with differences analysed using the $\chi^{2}$ test or Fisher's exact test, as appropriate. We calculated the sensitivity, specificity and predictive values of $\mathrm{T}$ wave inversion in lead aVL for predicting MLAD lesions (positive predictive value (PPV) and negative predictive value (NPV)). First, we examined the association between $T$ wave inversion in lead aVL regardless of other $\mathrm{T}$ wave changes and MLAD lesion. Second, we repeated the analysis focusing on isolated T wave inversion. ${ }^{4}$

For sensitivity analysis, we repeated the analysis after excluding the patients with left ventricular hypertrophy and bundle branch block because these are associated with $\mathrm{T}$ wave inversion. ${ }^{411}$ Data analyses were conducted using R statistical software V.3.0.3 (R Development Core Team, Vienna, Austria). All statistical tests were twotailed, and the chosen type 1 error rate was $\mathrm{p}<0.05$.

\section{RESULTS}

A total of 745 patients underwent PCI at the Ise Red Cross Hospital from January 2012 to December 2013. Among these, 263 patients underwent urgent PCI. Of 44 patients who did not meet the inclusion criteria, 2 patients did not undergo ECG before PCI, and 42 patients had complete occlusion of the left main trunk or proximal-segment left anterior descending artery; therefore, 219 patients were eligible for analysis (figure 1).

The median age of the patients was $71(63-78)$ years, and 167 patients were male $(76 \%$, table 1$)$. The most common coronary risk factors were hypertension $(74 \%)$, dyslipidaemia (65\%) and smoking (50\%). Of 219 patients, $137(63 \%)$ patients were diagnosed with ST-elevation myocardial infarction and the remaining 82 $(37 \%)$ patients were diagnosed with non-ST-elevation myocardial infarction (table 2). The right coronary artery was the site of the most frequent causative lesion, 
Figure 1 Flow chart of patients included in this study. ACS, acute coronary syndrome; CAG, coronary angiography; MLAD, mid-segment left anterior descending; $\mathrm{PCl}$, percutaneous coronary intervention.

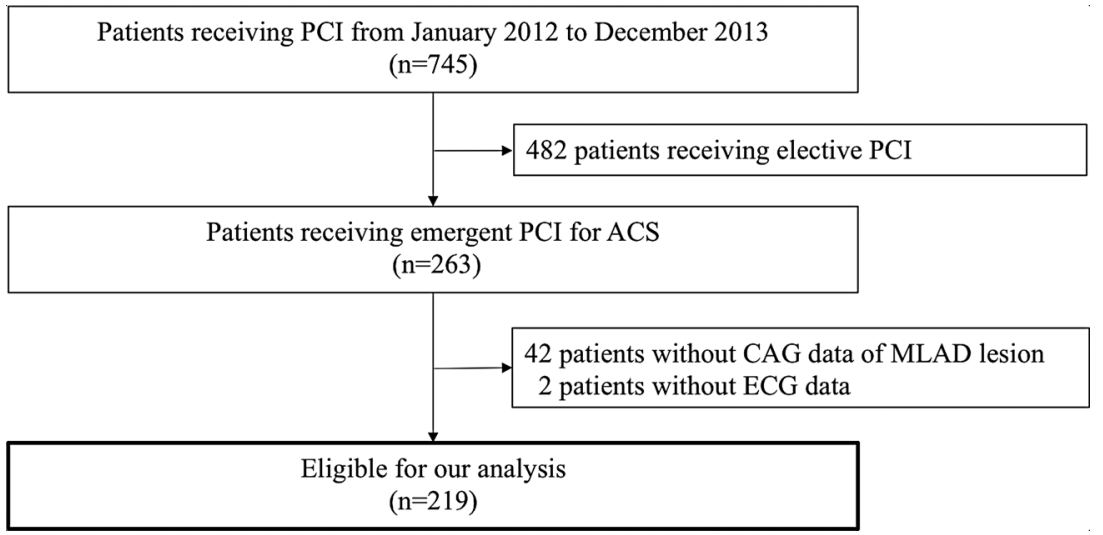

followed by the left anterior descending artery. Single-vessel disease was diagnosed in approximately half of the patients.

Among 219 patients, a total of 98 patients had $\mathrm{T}$ wave inversion in lead aVL regardless of other $\mathrm{T}$ wave changes and 26 patients had isolated $\mathrm{T}$ wave inversion in lead aVL (table 3). There was no difference in the time from symptom onset to initial ECG between patients with $\mathrm{T}$ wave inversion and those without (157 (97-293) min vs 173 (78-344) min; $p=0.85)$. Overall, 82 patients had a MLAD lesion $>50 \%$. $T$ wave inversion in lead aVL regardless of other $\mathrm{T}$ wave changes had a sensitivity of $32.9 \%$ (95\% CI $22.9 \%$ to $44.2 \%$ ), specificity of $48.2 \%$ (95\% CI $39.6 \%$ to $56.9 \%$ ), PPV of $27.6 \%$ (95\% CI $19.0 \%$ to $37.5 \%)$ and NPV of $54.5 \%$ (95\% CI $45.2 \%$ to $63.6 \%)$ for predicting MLAD lesions. By contrast, isolated $\mathrm{T}$ wave inversion in lead aVL had a sensitivity of $9.8 \%$ (95\% CI $4.3 \%$ to $18.3 \%$ ), specificity of $86.9 \%$ (95\% CI $80.0 \%$ to $92.0 \%)$, PPV of $30.8 \%$ (95\% CI $14.3 \%$ to $51.8 \%$ ) and NPV of $61.7 \%$ (95\% CI $54.4 \%$ to $68.5 \%)$ for predicting MLAD lesions. Focusing on patients with the MLAD lesion as the cause, $\mathrm{T}$ wave inversion in lead aVL regardless of other $\mathrm{T}$ wave changes had a sensitivity of $13.5 \%$ (95\% CI $4.5 \%$ to $28.8 \%$ ), specificity of $48.9 \%$

Table 1 Baseline characteristics of patients who underwent urgent percutaneous coronary intervention

\begin{tabular}{lc}
\hline Variables & $\begin{array}{c}\text { Overall } \\
(\mathbf{n}=\mathbf{2 1 9})\end{array}$ \\
\hline Age, median (IQR) & $71(63-78)$ \\
Male sex & $167(76)$ \\
Type of coronary risk factors & \\
Smoking & $110(50)$ \\
Family history of coronary artery diseases & $37(18)$ \\
Hypertension & $161(74)$ \\
History of myocardial infarction & $27(12)$ \\
Diabetes mellitus & $76(35)$ \\
Dyslipidaemia & $143(65)$ \\
$\quad$ Hyper triglyceride (TG) & $51(23)$ \\
Hyper low-density lipoprotein (LDL) & $89(41)$ \\
Low high-density lipoprotein (HDL) & $32(15)$ \\
\hline Data were expressed as n (\%) unless otherwise indicated.
\end{tabular}

(95\% CI $41.4 \%$ to $56.4 \%$ ), PPV of $5.1 \%$ (95\% CI $1.7 \%$ to $11.5 \%)$ and NPV of $73.6 \%$ (95\% CI $64.8 \%$ to $81.2 \%$ ) for predicting the MLAD lesion as the cause. By contrast, isolated $\mathrm{T}$ wave inversion in lead aVL had a higher specificity of $86.3 \%$ (95\% CI $80.4 \%$ to $90.9 \%$ ) for predicting the MLAD lesion as the cause.

In sensitivity analysis after excluding patients with left ventricular hypertrophy and bundle branch block, the performance of the $\mathrm{T}$ wave inversion in lead aVL regardless of other $\mathrm{T}$ wave changes for predicting MLAD lesions did not change materially (table 4). Focusing on patients with the MLAD lesion as the cause, isolated $\mathrm{T}$ wave inversion in lead aVL had a higher specificity of $85.6 \%(95 \%$ CI $78.2 \%$ to $91.2 \%)$ for predicting the MLAD lesion as the cause.

\section{DISCUSSION}

In this retrospective study using data from the CAG database at the Ise Red Cross Hospital from January 2012 to

Table 2 Angiographic data of patients who underwent urgent percutaneous coronary intervention

\begin{tabular}{lc}
\hline Variables & Overall (n=219) \\
\hline ST-elevation myocardial infarction & $137(63)$ \\
Non-ST-elevation myocardial infarction & $82(37)$ \\
Causative lesion & \\
Right coronary artery & $101(46)$ \\
Left main trunk & $5(2)$ \\
Left anterior descending artery & $78(36)$ \\
Left circumflex artery & $32(15)$ \\
High lateral branch & $3(1)$ \\
Coronary lesions & \\
Single-vessel disease & $101(46)$ \\
Double-vessel disease & $65(30)$ \\
Triple-vessel disease & $53(24)$ \\
Number of lesions in left anterior descending artery* \\
0 & $86(39)$ \\
1 & $108(49)$ \\
2 & $23(11)$ \\
3 & $2(1)$ \\
\hline Data were expressed as $n$ (\%). & \\
*Number of lesions in left anterior descending artery does not \\
include diagonal branch.
\end{tabular}


Table 3 Performance of T wave inversion in lead aVL for predicting mid-segment left anterior descending lesion

\begin{tabular}{|c|c|c|c|c|}
\hline MLAD lesion & $\begin{array}{l}\text { Overall } \\
(\mathrm{n}=219)\end{array}$ & $\begin{array}{l}\text { MLAD }>50 \% \\
n=82\end{array}$ & $\begin{array}{l}\text { MLAD } \leq 50 \% \\
n=137\end{array}$ & p Value \\
\hline $\begin{array}{l}\text { T wave inversion in lead aVL regardless of other } T \text { wave changes* } \\
\text { Isolated T wave inversion in lead aVL } †\end{array}$ & $\begin{array}{l}98(45) \\
26(12)\end{array}$ & $\begin{array}{r}27(33) \\
8(10)\end{array}$ & $\begin{array}{l}71(52) \\
18(13)\end{array}$ & $\begin{array}{r}<0.01 \\
0.59\end{array}$ \\
\hline MLAD lesion as the cause & $\begin{array}{l}\text { Overall } \\
(n=219)\end{array}$ & $\begin{array}{l}\text { Cause }(+) \\
\mathrm{n}=37\end{array}$ & $\begin{array}{l}\text { Cause (-) } \\
\mathrm{n}=182\end{array}$ & p Value \\
\hline $\begin{array}{l}\text { T wave inversion in lead aVL regardless of other T wave changes } \neq \\
\text { Isolated T wave inversion in lead aVL§ }\end{array}$ & $\begin{array}{l}98(45) \\
26(12)\end{array}$ & $\begin{array}{l}5(14) \\
1(3)\end{array}$ & $\begin{array}{l}93(51) \\
25(14)\end{array}$ & $\begin{array}{r}<0.01 \\
0.09\end{array}$ \\
\hline
\end{tabular}

Data were expressed as $\mathrm{n}(\%)$.

*Sensitivity $32.9 \%$ (95\% Cl $22.9 \%$ to $44.2 \%$ ), specificity $48.2 \%$ (95\% Cl 39.6\% to $56.9 \%$ ), positive predictive value $27.6 \%$ (95\% Cl $19.0 \%$ to $37.5 \%)$ and negative predictive value $54.5 \%(95 \% \mathrm{Cl} 45.2 \%$ to $63.6 \%)$.

†Sensitivity $9.8 \%$ (95\% Cl $4.3 \%$ to $18.3 \%$ ), specificity $86.9 \%$ (95\% Cl $80.0 \%$ to $92.0 \%$ ), positive predictive value $30.8 \%(95 \%$ Cl $14.3 \%$ to $51.8 \%$ ) and negative predictive value $61.7 \%$ (95\% Cl $54.4 \%$ to $68.5 \%)$.

¥Sensitivity $13.5 \%$ (95\% Cl $4.5 \%$ to $28.8 \%$ ), specificity $48.9 \%$ (95\% Cl $41.4 \%$ to $56.4 \%$ ), positive predictive value $5.1 \%(95 \% \mathrm{Cl} 1.7 \%$ to $11.5 \%)$ and negative predictive value $73.6 \%(95 \% \mathrm{Cl} 64.8 \%$ to $81.2 \%)$.

§Sensitivity $2.7 \%(95 \% \mathrm{Cl} 0.1 \%$ to $14.2 \%)$, specificity $86.3 \%$ (95\% Cl $80.4 \%$ to $90.9 \%)$, positive predictive value $3.8 \%(95 \% \mathrm{Cl} 0.1 \%$ to

$19.6 \%$ ) and negative predictive value $81.3 \%$ (95\% Cl $75.1 \%$ to $86.6 \%$ ).

MLAD, mid-segment left anterior descending artery.

December 2013, we found that, among patients with ACS, the diagnostic value of $\mathrm{T}$ wave inversion in lead aVL regardless of other $\mathrm{T}$ wave changes for predicting MLAD lesions was unsatisfactory. However, isolated $T$ wave inversion in lead aVL had high specificity for predicting MLAD lesions, even after excluding patients with left ventricular hypertrophy and bundle branch block. To the best of our knowledge, this is the first study to evaluate the diagnostic value of $\mathrm{T}$ wave inversion in lead aVL for MLAD lesions among patients who underwent urgent PCI for ACS.

T wave inversion in ECG is vital to the early diagnosis and detection of ischaemic lesions in patients with suspected ACS. Reciprocal changes in ECG are recognised earlier than the ST elevation as the reflection of the ischaemic lesion in ACS, ${ }^{2}{ }^{3}$ and $6 \%$ of patients with ACS had only reciprocal changes without ST elevation. ${ }^{3}$ To date, several studies have focused on the diagnostic values of $\mathrm{T}$ wave inversion for predicting MLAD lesions. ${ }^{4512}$ Among patients with chronic stable angina, the OR of $\mathrm{T}$ wave inversion in lead aVL for predicting MLAD lesions was $2.93 .^{5} \mathrm{In}$ another study, T wave inversion in leads aVL and I had a sensitivity of $86.5 \%$ and specificity of $55.6 \%$ for predicting MLAD lesions. ${ }^{4}$ However, in our study, $\mathrm{T}$ wave inversion in lead aVL regardless of other $\mathrm{T}$ wave changes had a low sensitivity of $32.9 \%$ and a specificity of $48.2 \%$ for predicting MLAD lesions.

The reasons for the disparities in the diagnostic values among studies are likely multifactorial. First, although the definition of $\mathrm{T}$ wave inversion was unclear in previous studies, ${ }^{5} 612$ we clearly defined $\mathrm{T}$ wave

Table 4 Performance of T wave inversion in lead aVL for predicting mid-segment left anterior descending lesion, after excluding patients with left ventricular hypertrophy and bundle branch block

\begin{tabular}{|c|c|c|c|c|}
\hline MLAD lesion & $\begin{array}{l}\text { Overall } \\
(n=154)\end{array}$ & $\begin{array}{l}\text { MLAD }>50 \% \\
\mathrm{n}=58\end{array}$ & $\begin{array}{l}\text { MLAD } \leq 50 \% \\
n=96\end{array}$ & p Value \\
\hline $\begin{array}{l}\text { T wave inversion in lead aVL regardless of other } \mathrm{T} \text { wave changes* } \\
\text { Isolated } \mathrm{T} \text { wave inversion in lead aVL } \dagger\end{array}$ & $\begin{array}{l}65(42) \\
19(12)\end{array}$ & $\begin{array}{c}18(31) \\
5(9)\end{array}$ & $\begin{array}{l}47(49) \\
14(15)\end{array}$ & $\begin{array}{l}0.04 \\
0.40\end{array}$ \\
\hline MLAD lesion as the cause & $\begin{array}{l}\text { Overall } \\
(n=154)\end{array}$ & $\begin{array}{l}\text { Cause (+) } \\
n=29\end{array}$ & $\begin{array}{l}\text { Cause (-) } \\
\mathrm{n}=125\end{array}$ & p Value \\
\hline $\begin{array}{l}\text { T wave inversion in lead aVL regardless of other } \mathrm{T} \text { wave changes } \ddagger \\
\text { Isolated } \mathrm{T} \text { wave inversion in lead } \mathrm{aVL} \S\end{array}$ & $\begin{array}{l}65(42) \\
19(12)\end{array}$ & $\begin{array}{l}4(14) \\
1(3)\end{array}$ & $\begin{array}{l}61(49) \\
18(14)\end{array}$ & $\begin{array}{l}<0.01 \\
0.13\end{array}$ \\
\hline \multicolumn{5}{|c|}{ 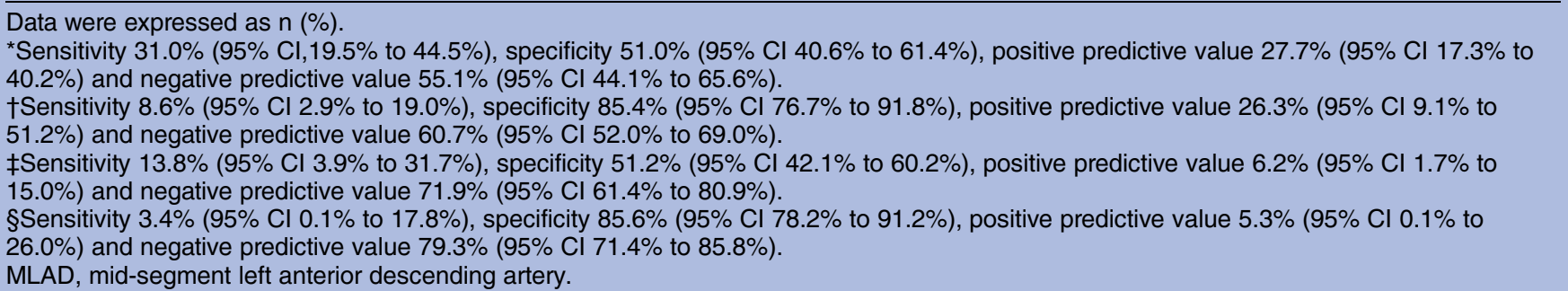 } \\
\hline
\end{tabular}


inversion according to the AHA definition; ${ }^{9}$ therefore, our findings were less likely to be subject to information bias. Second, a previous study used a combination of $\mathrm{T}$ wave inversion in lead aVL and lead I to estimate the diagnostic values. ${ }^{4}$ Third, the disparities in the diagnostic values may be attributable to the differences in study population, settings, or any combination of these factors. For example, the study by Farhan $e t a l l^{5}$ which reported the effectiveness of $\mathrm{T}$ wave inversion in lead aVL in diagnosing coronary artery disease, was limited to patients with chronic stable angina. Another study included patients who underwent non-urgent PCI (ie, elective PCI). ${ }^{4}$ Fourth, in general, multivessel lesions cause complicated ECG changes, thereby the differences in the proportions of multivessel lesions compared with previous studies may have been influential. ${ }^{2}$ Indeed, the previous two studies had more multivessel lesions than our study did, (53.9\% in our study vs $61.2 \%$ in Farhan's study, $\mathrm{p}=0.16$; and vs $70.7 \%$ in Hassen's study, $\mathrm{p}<0.01) .{ }^{45}$

Although we did not show the diagnostic usefulness of $\mathrm{T}$ wave inversion in lead aVL regardless of other $\mathrm{T}$ wave changes, isolated $\mathrm{T}$ wave inversion in lead aVL (ie, the presence of $\mathrm{T}$ wave inversion only in lead $\mathrm{aVL}$ ) had a high specificity of $86.9 \%$ for predicting MLAD lesions. Since treatment strategy and complications depend on the infarction site, ${ }^{7}$ isolated $\mathrm{T}$ wave inversion in lead aVL might help to predict the site of the ischaemic lesion, resulting in improved patient outcome. Moreover, previous studies reported that approximately $75 \%$ of physicians missed an isolated $\mathrm{T}$ wave inversion in lead $\mathrm{aVL}$ and that the best single lead for the emergency detection of ACS was lead aVL. ${ }^{12}{ }^{13}$ In agreement with this literature, our findings underscore the importance of cautious interpretation of $\mathrm{T}$ wave inversion in lead aVL as a clue to predict ischaemic lesions in ACS.

\section{Limitations}

Our study has several potential limitations. First, because this study is a single-centre study, the generalisability of our inferences is limited. Nevertheless, we analysed the consecutive data during 2012-2013 with the definition of $\mathrm{T}$ wave inversion based on AHA guidelines. ${ }^{9}$ Moreover, all $\mathrm{T}$ wave inversions were evaluated by cardiologists who were blinded to the results of the PCIs. Second, this study is limited by the small sample size. In particular, isolated $\mathrm{T}$ wave inversion was observed in only $12 \%$ of patients; therefore, our observations should be validated by a larger study. Third, in this analysis, we did not measure the association between $\mathrm{T}$ wave inversion and diagonal lesions. ${ }^{14}$ However, to maintain the consistency with the previous literature, ${ }^{4}{ }^{5}$ we focused on the association between $\mathrm{T}$ wave inversion in lead aVL and MLAD lesion regardless of the presence of diagonal lesions. Fourth, as with any other observational studies focused on patients with ACS, we could not differentiate whether the MLAD lesion had or had not newly occurred. However, our inferences were not changed materially among patients with ACS caused by the MLAD lesion. Finally, we included patients who underwent PCI. Therefore, our inferences should be used for predicting ischaemic lesions, and not for diagnosing ACS.

\section{CONCLUSIONS}

In our study, $\mathrm{T}$ wave inversion in lead aVL regardless of other $\mathrm{T}$ wave changes had low sensitivity and specificity for predicting MLAD lesions. However, isolated T wave inversion in lead aVL had high specificity. Our inferences underscore the importance of a cautious interpretation of $\mathrm{T}$ wave inversion in lead aVL among patients with suspected ACS. In addition, our findings facilitate further studies to validate the diagnostic values of $\mathrm{T}$ wave inversion in lead aVL for predicting ischaemic lesions.

Acknowledgements The authors acknowledge the Japanese Emergency Medicine Network (JEMNet) and the cardiologist at Ise Red Cross Hospital, for designing and helping this research.

Contributors NN was involved in study concept and design, analysis and interpretation of the data and drafting of the manuscript. TG took part in study concept and design, analysis and interpretation of the data and drafting of the manuscript. TI was involved in acquisition of the data. AK took part in analysis and interpretation of the data and critical revision of the manuscript for important intellectual content.

Funding This research received no specific grant from any funding agency in the public, commercial or not-for-profit sectors.

Competing interests None declared.

Ethics approval Ise Red Cross Hospital.

Provenance and peer review Not commissioned; externally peer reviewed.

Data sharing statement No additional data are available.

Open Access This is an Open Access article distributed in accordance with the Creative Commons Attribution Non Commercial (CC BY-NC 4.0) license, which permits others to distribute, remix, adapt, build upon this work noncommercially, and license their derivative works on different terms, provided the original work is properly cited and the use is non-commercial. See: http:// creativecommons.org/licenses/by-nc/4.0/

\section{REFERENCES}

1. Zimetbaum PJ, Josephson ME. Use of the electrocardiogram in acute myocardial infarction. N Engl J Med 2003;348:933-40.

2. Kracoff $\mathrm{OH}$, Adelman AG, Marquis JF, et al. Twelve-lead electrocardiogram recording during percutaneous transluminal coronary angioplasty. Analysis of reciprocal changes. $J$ Electrocardiol 1990;23:191-8.

3. Kracoff $\mathrm{OH}$, Adelman AG, Oettinger M, et al. Reciprocal changes as the presenting electrocardiographic manifestation of acute myocardial ischemia. Am J Cardiol 1993;71:1359-62.

4. Hassen GW, Costea A, Smith $\mathrm{T}$, et al. The neglected lead on electrocardiogram: T wave inversion in lead aVL, nonspecific finding or a sign for left anterior descending artery lesion? J Emerg Med 2014;46:165-70.

5. Farhan HL, Hassan KS, Al-Belushi A, et al. Diagnostic value of electrocardiographic $\mathrm{T}$ wave inversion in lead $\mathrm{aVL}$ in diagnosing coronary artery disease in patients with chronic stable Angina. Oman Med J 2010;25:124-7.

6. Hassen GW, Talebi S, Fernaine G, et al. Lead aVL on electrocardiogram: emerging as important lead in early diagnosis of myocardial infarction? Am J Emerg Med 2014;32:785-8.

7. O'Gara PT, Kushner FG, Ascheim DD, et al. 2013 ACCF/AHA guideline for the management of ST-elevation myocardial infarction: 
a report of the American College of Cardiology Foundation/American Heart Association Task Force on Practice Guidelines. Circulation 2013;127:e362-425.

8. Mehta SR, Granger CB, Boden WE, et al. Early versus delayed invasive intervention in acute coronary syndromes. $N$ Engl $\mathrm{J}$ Med 2009;360:2165-75.

9. Rautaharju PM, Surawicz B, Gettes LS, et al. AHA/ACCF/HRS recommendations for the standardization and interpretation of the electrocardiogram: part IV: the ST segment, T and U waves, and the QT interval: a scientific statement from the American Heart Association Electrocardiography and Arrhythmias Committee, Council on Clinical Cardiology; the American College of Cardiology Foundation; and the Heart Rhythm Society: endorsed by the International Society for Computerized Electrocardiology. Circulation 2009;119:e241-50.

10. Austen WG, Edwards JE, Frye RL, et al. A reporting system on patients evaluated for coronary artery disease. Report of the Ad Hoc
Committee for Grading of Coronary Artery Disease, Council on Cardiovascular Surgery, American Heart Association. Circulation 1975;51:5-40.

11. Hayden GE, Brady WJ, Perron AD, et al. Electrocardiographic T-wave inversion: differential diagnosis in the chest pain patient. Am J Emerg Med 2002;20:252-62.

12. Hassen GW, Costea A, Carrazco C, et al. Isolated T Wave Inversion in Lead aVL: an ECG Survey and a Case Report. Emerg Med Int 2015;2015:250614.

13. Green M, Ohlsson M, Forberg JL, et al. Best leads in the standard electrocardiogram for the emergency detection of acute coronary syndrome. J Electrocardiol 2007;40:251-6.

14. Birnbaum $Y$, Hasdai $D$, Sclarovsky $S$, et al. Acute myocardial infarction entailing ST-segment elevation in lead aVL: electrocardiographic differentiation among occlusion of the left anterior descending, first diagonal, and first obtuse marginal coronary arteries. Am Heart J 1996;131:38-42. 